\title{
Ulcerative colitis in a husband and wife
}

\author{
G M Batty, W E Wilkins, J S Morris
}

\begin{abstract}
The case histories of a husband and wife who developed ulcerative colitis after 28 years of marriage are described. It is hoped this report will stimulate the systematic study of inflammatory bowel disease occurring in both partners of a marriage and clarify the comparative importance of constitutional and environmental factors in its pathogenesis.

(Gut 1994; 35: 562-563)
\end{abstract}

If both partners of a marriage develop identical diseases it lends support to the possibility that environmental factors precipitate or cause it.

In the United Kingdom there are six reports of married couples who have Crohn's disease. ${ }^{1-5}$ This suggests a common environmental factor, possibly an infection, which precipitates the presentation of the disease or causes it. ${ }^{5}$ Reports of ulcerative colitis in married couples are few and a review of published works has shown one previously recorded example of the condition occurring in an Italian husband and wife ${ }^{6}$ and three cases in the USA. ${ }^{78}$

Assuming a prevalence of $1 \cdot 5 / 1000$ head of population for ulcerative colitis, the probability that both husband and wife have the disease is $(1 \cdot 5 / 1000)^{2}$ - assuming these events are independent. As there are 12 million married couples in England and Wales (1990 OPCS), we would expect 27 couples to suffer from ulcerative colitis. If a prevalence of Crohn's disease of $0.5 /$ 1000 head of population is assumed, a coincidental relation of inflammatory bowel disease between husband and wife should occur more often in ulcerative colitis if the association occurs just by chance. The reverse is the case, however, implying that environmental factors are unimportant in ulcerative colitis. Alternatively a false impression of low frequency may be a result of the association being seldom reported.

\section{Case report 1}

The index case was born in Maesteg, South Wales in 1923 and is a lifelong non-smoker. There was no family history of inflammatory bowel disease. He first presented in 1970 at the age of 47 with bloody diarrhoea and loose stools. Sigmoidoscopy at the time showed moderate colitis. His symptoms settled without treatment and did not recur during a three year follow up period at the end of which time he was discharged.

In 1988 he was referred to the clinic with a three month history of diarrhoea with blood and slime. A barium enema showed total colitis and a colonoscopy and a biopsy (Fig 1) confirmed ulcerative colitis. His symptoms were controlled after treatment with a short course of oral

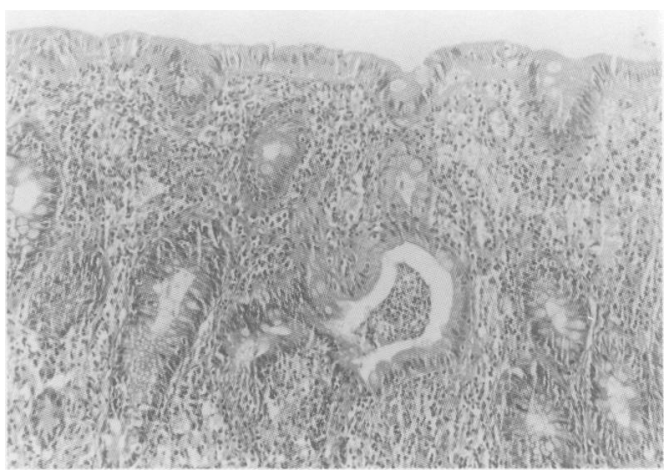

Figure 1: Colonic mucosa with a severe, mixed inflammatory infiltrate and a crypt abscess. Haematoxylin and eosin (green filter original magnification $\times 165$ ).

steroids and longterm salazopyrine. He has no symptoms four years later.

\section{Case report 2}

His wife was also born in Maesteg in 1928. Her parents were Italian and had immigrated in the early 1920s removing any possibility of consanguinity. She married in 1961 at the age of 33 and had two sons in 1962 and 1963. She is a nonsmoker and had never taken oral contraception. There was no family history of inflammatory bowel disease.

In 1989, six months after her husband's relapse she presented for the first time with bloodstained diarrhoea and colicky abdominal pain. Stool culture was negative and there was no evidence of ova or cysts on microscopy. There were typical appearances of ulcerative colitis at sigmoidoscopy and the condition was confirmed at biopsy examination. Barium enema examination showed total colitis (Fig 2). Her symptoms resolved with oral steroid treatment and maintenance salazopyrine. She is free of symptoms three years later.

The Table lists the relevant dates of the development or recurrence of disease in both patients and their HLA state.

\section{Discussion}

As Crohn's disease seems to occur more commonly than ulcerative colitis among married couples in the United Kingdom it may be that

Development and recurrence of ulcerative colitis

\begin{tabular}{llc}
\hline & Husband & Wife \\
\hline Year of birth & 1923 & 1928 \\
Year of onset & 1970 & 1989 \\
Year of recurrence & 1990 & - \\
HLA B27 state & $-\mathrm{ve}$ & $-\mathrm{ve}$ \\
\hline
\end{tabular}

\section{Tospital, Bridgend W E Wilkins Dr G M Batty, Princess of Wales \\ Hospital, Coity Road, \\ Bridgend, Mid Glamorgan \\ Accepted for publication \\ 9 August 1993}




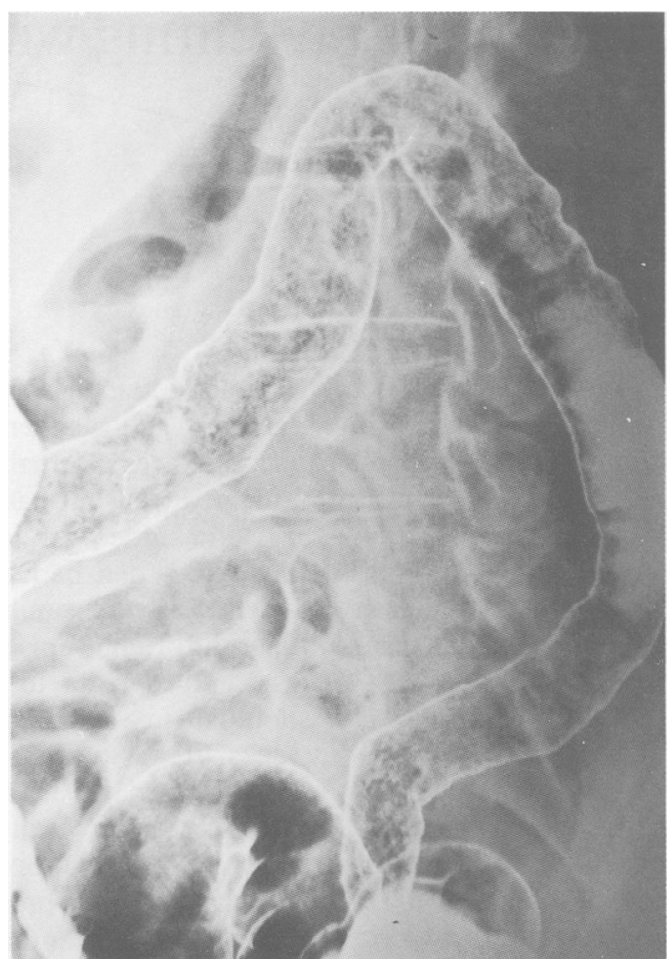

Figure 2: Barium enema showing loss of haustral pattern and superficial ulceration in descending and transverse colon.

environmental factors are unimportant in ulcerative colitis. It is possible that, because ulcerative colitis is more common, examples of the disease occurring in both partners of the marriage are not reported.

In this report the close temporal relation between disease recurrence in the husband and the diagnosis for the first time of the condition in his wife suggests an environmental cause. There were no specific features that may have made the couple more susceptible to inflammatory bowel disease. There was no distant family connection between the couple as the wife was the first generation of her family to be born in Wales. Enquiries about their diet, did not show unusual eating patterns. Their diet has never contained a high intake of simple sugars and they deny any non-narcotic analgesic abuse. ${ }^{910}$ They were both breast fed although we could not establish when each was weaned. ${ }^{11}$ Their social circumstances had not changed in the two years before the diagnosis other than that the husband had retired. This could have increased their common exposure to an environmental agent.

Identifying factors that cause ulcerative colitis or lead to its relapse has been the subject of debate over recent years. This report suggests that environmental factors may play a part, but our evidence is inconclusive. We believe the establishment of a national register of married couples with ulcerative colitis might help to identify environmental factors of possible importance in causing or precipitating the condition. The publication of further resports of the coincidence of the disease in married couples would be of interest.

We are grateful to Dr A Rees, consultant pathologist, Dr D Foster, consultant radiologist, and Mrs $\mathbf{K}$ Gallimore, district Foster, consultant radiologist, and Mrs $K$ Gallimore, district Griffiths from the Faculty of Physical Sciences, University of Griffiths from the Faculty of Physical
Wales College of Cardiff for their help.

1 Whorwell PJ, Eade OE, Hossenbockus A, Bamforth J. Crohn's disease in a husband and wife. Lancet 1978; ii Crohn's

2 Whorwell PJ, Hodges JR, Bamforth J, Wright R. Crohn's disease in a husband and wife. Lancet 1981; i: 334-5.

3 Rhodes JM, Marshall T, Hamer JD, Allan RN. Crohn's disease in two married couples. Gut 1985; 26: 1086-7.

4 Holmes GKT, Painter NS. Crohn's disease in married couples (letter). Gut 1986; 27: 350.

5 Lobo AJ, Foster PN, Sobala GM, Axon ATR. Crohn's disease in married couples. Lancet 1988; i: 704-5.

6 Craxi A, Oliva L, Di Stenfano G. Ulcerative colitis in a married couple. Ital F Gastroenterol 1979; 11: $184-6$.

7 Bennet RA, Rubin PH, Present DH. Frequency of inflammatory bowel disease in offspring of couples both presenting with inflammatory bowel disease. Gastroenterology 1991; with inflammatc

8 Almy TP, Sherlock P. Genetic aspects of ulcerative colitis and regional enteritis. Gastroenterology 1966; 51: 7 .

9 Thornton JR, Emmett PM, Heaton KW. Diet and Crohn's disease: characteristics of the pre-illness diet. BMF 1979; ii: 762-4.

10 Rampton DS, McNeil NI, Sarner M. Analgesic ingestion and other factors preceding relapse in ulcerative colitis. $G u$ 1983; 24: 187-9.

11 Acheson ED, Truelove SC. Early weaning in the aetiology of ulcerative colitis. A study of feeding in infancy in cases and controls. BMF 1961; 2: 929-33. 